\title{
RECONHECENDO A ALTERIDADE DO ANALISTA - UMA CARACTERIZAÇÃO DO TRABALHO ANALÍTICO FUNDAMENTADO NO CUIDADO
}

\author{
RECOGNIZING THE ANALYST'S ALTERITY - A \\ CHARACTERIZATION OF ANALYSIS BASED ON CARE \\ RECONOCIENDO LA ALTERIDAD DEL ANALISTA - UNA \\ CARACTERIZACIÓN DEL TRABAJO ANALÍTICO BASADO EN EL CUIDADO
}

Estela Ribeiro Versiani* Luiz Augusto M. Celes**

\section{RESUMo}

Considera-se que a análise modificada proposta por Winnicott é um trabalho analítico que se norteia pelo cuidado. $O$ trabalho da análise modificada é compreendido a partir da noção winnicottiana de uso de objeto. Para que um objeto seja usado, é necessário que seja lançado fora do domínio subjetivo, permitindo-lhe uma alteridade. A análise modificada pode possibilitar ao analisando aprender a "usar o analista", o que supóe que, a partir da análise, esse analista poderá passar a existir fora da área de fenômenos subjetivos do analisando e como representante de uma alteridade. Fornecendo um ambiente suficientemente bom e permitindo a correção de certas falhas ambientais, assim como a expressão da atividade criativa do analisando, a análise modificada pode tornar possível ao analisando a constituição do analista enquanto objeto objetivo e o reconhecimento de sua alteridade. A partir daí, o analisando poderá usar o analista e suas interpretações.

Palavras-chave: alteridade; análise modificada; uso de objeto.

\section{Abstract}

It is suggested that modified analysis, as proposed by Winnicott, is an analysis based on care. The task of modified analysis is understood by means of

\footnotetext{
* Escola Superior de Ciências da Saúde do Distrito Federal, Brasília, DF, Brasil.

** Universidade de Brasília, Brasília, DF, Brasil.
} 
Winnicott's concept of the use of an object. For an object to be used it has to be put outside the subjective domain, gaining thus an alterity. In modified analysis, the patient will learn to "use the analyst", which implies that the analyst will be able to exist outside the patient's subjective area, therefore representing an alterity. By providing a good enough environment and allowing the correction of certain environmental faults and the expression of the patient's creativity, modified analysis makes possible the constitution of the analyst as an objective object and the recognition, by the patient, of the analyst's alterity. From then on, the patient will be able to use the analyst and the analyst's interpretations.

Keywords: alterity; modified analysis; use of an object.

\section{RESUMEN}

Se considera que el análisis modificado propuesto por Winnicott es un trabajo analítico que se nortea por el cuidado. El trabajo del análisis modificado se comprende a partir de la noción winnicottiana de uso del objeto. Para que un objeto sea utilizado, es necesario que sea lanzado fuera del dominio subjetivo, permitiéndose una alteridad. El análisis modificado puede posibilitar al analizado el aprender a "utilizar el analista", lo que supone que, a partir del análisis, ese mismo analista podrá pasar a existir fuera del área de fenómenos subjetivos del analizado y como representante de una alteridad. Al ofrecer un ambiente suficientemente bueno y al permitir la corrección de ciertos fallos ambientales, así como la expresión de la actividad creativa del analizado, el análisis modificado puede hacer posible, al analizado, la constitución del analista como objeto objetivo y el reconocimiento de su alteridad. A partir de ello, el analizado podrá utilizar el analista y sus interpretaciones.

Palabras clave: alteridad; análisis modificado; uso del objeto.

Grande parte da clínica de Winnicott foi composta de casos que, muitas vezes, se mostravam incompatíveis com a prática do que ele, em texto de 1962, chamou de "análise padrão" (standard analysis). Tais casos necessitavam de outra abordagem, fosse esta uma "análise modificada" (Winnicott, 1962/1990, p. 168) ou até, em determinados momentos, um "trabalho não-analítico" (Winnicott, 1962/1990, p. 169). Em que consistiria exatamente esse trabalho do analista que não está praticando a análise padrão é uma das questôes que Winnicott procurou elucidar e descrever em vários de seus textos. 
Nessas análises "modificadas", consideramos que o trabalho do analista se inscreve como cuidado (Figueiredo, 2009; Souza, 2007), constituindo-se como um trabalho que, diante de uma falha do meio ambiente percebida pelo analisando como traumática, procura, "a partir do desenvolvimento de uma relação transferencial de confiança, apenas fazer com que o emprego de certas defesas [pelo analisando] se torne desnecessário" (Souza, 2007, p. 337).

Procuraremos, a seguir, caracterizar melhor tal trabalho de análise a partir da noção winnicottiana de uso de objeto.

\section{O uso de um objeto}

Foi numa conferência proferida em 1968 perante a Sociedade Psicanalítica de Nova York que Winnicott fez sua principal exposição acerca da noção de uso de objeto. Uma versão ligeiramente modificada dessa conferência foi posteriormente publicada - primeiro em $O$ brincar e a realidade e depois em Exploraçóes psicanaliticas.

Logo no início do texto "O uso de um objeto e o relacionamento através de identificações”, Winnicott (1971/1982) tece algumas consideraçôes sobre a interpretação analítica e estabelece uma relação entre interpretação e uso de objetos:

[a interpretação], se for ter efeito, deve estar relacionada à habilidade do paciente de colocar o analista fora da área de fenômenos subjetivos. O que está entáo implicado é a habilidade do paciente de usar o analista [...] no nosso trabalho é necessário que estejamos preocupados com o desenvolvimento e o estabelecimento da capacidade de usar objetos e que reconheçamos a inabilidade de um paciente de usar objetos, quando isso for um fato (Winnicott, 1971/1982, p. 87).

Winnicott, assim, ressalta a importância de o analista saber diferenciar entre o paciente que possui e o que não possui a capacidade de usar objetos, pois isso determinará a forma como a análise será conduzida. No caso do segundo grupo de pacientes, a análise irá caminhar, pelo menos inicialmente, no sentido de permitir que esses pacientes adquiram a referida capacidade.

Outro ponto importante é a relação a que Winnicot faz referência entre a capacidade do paciente de usar o analista e sua capacidade de "colocar o analista fora da área de fenômenos subjetivos". Para que um analista possa ser usado, é necessário que ele esteja fora da área de fenômenos subjetivos do analisando, 
e que o analisando, portanto, seja capaz de reconhecer seu analista como um objeto externo, que existe independentemente de suas identificaçóes projetivas, fazendo parte, assim, da realidade externa. Pois, para Winnicott, há uma fase do desenvolvimento em que o objeto se constitui principalmente por meio de identificações projetivas, não sendo concebido ainda como possuindo uma existência independente. Nessa fase, o objeto ainda não pode ser usado, já que, de acordo com Winnicott (1971/1982), para ser usado, o objeto deve necessariamente ser parte da realidade compartilhada.

Sendo assim, a relação de objeto (object-relating) a que Winnicott (1971/1982) compara o uso de objeto (object-usage) é uma relação de objeto em que este não é compreendido como tendo uma existência independente do sujeito - daí ser um “objeto subjetivo”. Como explica Safra (1999, p. 34), “o objeto é primeiro subjetivo para depois ser objetivamente percebido. [...] O objeto subjetivo acontece em um campo de experiência onipotente, em que não há diferenciação entre o eu e o não-eu”.

Muitos analisandos já chegam para análise, desde o início, com a apreensão do analista, e de outros objetos, como objetos objetivos, que fazem parte da realidade compartilhada. Para outros pacientes, porém - ou mesmo em momentos específicos da análise de um paciente que em geral não tem dificuldade de apreender os objetos independentemente dele -, colocar o analista fora da área de controle onipotente não é uma tarefa simples, embora seja imprescindível para o andamento da análise. Nesses casos, tal mudança na colocação do analista deve resultar do próprio processo de análise, na medida em que deixa ver uma diferenciação entre analista e analisando.

Ao se referir à mudança, por parte do sujeito, da relação de objeto (object-relating) para o uso de objeto (object-usage), Winnicott propóe que o que acontece é uma destruição do objeto. Como ele diz, "esta mudança (de relação para uso) significa que o sujeito destrói o objeto" (Winnicott, 1971/1982, p. 89). O que Winnicott nomeia como destruição do objeto está diretamente relacionado ao fato de esse objeto se tornar externo, independente das projeçôes do sujeito. Nas palavras de Ogden (1996, p. 52), ao destruir a mãe, “o bebê abre espaço para a possibilidade da mãe como sujeito, uma pessoa diferente-de-mim, destruindo um aspecto dele mesmo (sua própria onipotência projetada no objeto interno mãe onipotente)". Além disso, para que o objeto possa em seguida ser usado, Winnicott ressalta ser necessário que ele "sobreviva" à sua própria destruição. O que está em jogo, assim, é tanto o impulso destrutivo do sujeito como um movimento de sobrevivência do objeto - o que deixa ver a importância que é dada ao ambiente, que não é visto apenas como receptor dos impulsos do sujeito. A destruição da 
mãe pelo bebê implica, portanto, também um movimento de sobrevivência por parte dessa mãe.

As palavras de Winnicott são as seguintes: "Depois de 'sujeito se relaciona com objeto' vem 'sujeito destrói objeto' (ao se tornar externo); e depois poderá vir 'objeto sobrevive a destruição pelo sujeito'. Mas poderá ou não haver sobrevivência” (Winnicott, 1971/1982, p. 90). Se houver sobrevivência do objeto, o caminho estará livre para que ele possa ser usado. E, como se estivesse prevendo uma reação de estranheza a sua ideia de o objeto "sobreviver à destruição", Winnicott esclarece: “'Sobreviver', nesse contexto, significa 'não retaliar” (Winnicott, 1971/1982, p. 91).

Em relação à destruição do objeto, Winnicott comenta que a questão não é apenas a de que o sujeito destrói o objeto porque o reconhece fora de sua área de controle onipotente, mas também a de que a própria destruição do objeto irá posicioná-lo fora dessa área. Nessa fase, os objetos estão "no processo de virem a ser destruídos por serem reais e de se tornarem reais por serem destruídos" (Winnicott, 1971/1982, p. 90). A partir daí, ou resultando dessa fase, o objeto estará sempre sendo destruído inconscientemente, na fantasia. Segundo Winnicott, é isso que irá fornecer a qualidade de realidade e de constância ao objeto. Tal movimento contínuo de destruição do objeto deixa entender que essa destruição nunca é completa, retornando sempre por formar a primeiríssima base sobre a qual o sujeito se constitui a partir da presença e cuidados do outro. Para Ogden (1996, p. 53), "ao destruir continuamente (na fantasia) o objeto-interno-mãe, o bebê torna-se capaz de descobrir o objeto-externo-mãe".

\section{Destruição e sobrevivência do analista}

Os impulsos destrutivos do analisando em direção ao analista podem aparecer sob a forma, por exemplo, de agressóes verbais ou mesmo de um boicote à análise, seja por meio de faltas, atrasos ou longos períodos de silêncio. $\mathrm{O}$ que Winnicott irá ressaltar é a importância de o analista suportar e sobreviver a esses ataques - lembrando que sobreviver, para ele, implica não retaliar -, pois essa atividade destrutiva é "a tentativa do paciente de colocar o analista fora da área de controle onipotente" (Winnicott, 1971/1982, p. 91) - tentativa de dessubjetivá-lo, por assim dizer. Sem uma experiência de destrutividade, "o sujeito nunca coloca o analista do lado de fora e, portanto, nunca pode fazer mais do que experienciar um tipo de autoanálise" (Winnicott, 1971/1982, p. 91).

Além de não retaliar, Winnicott chama a atenção para a importância de o analista, nessa fase da análise, refrear sua ânsia interpretativa: "O analista tem von- 
tade de interpretar, mas isso pode estragar o processo, e para o paciente pode parecer um tipo de autodefesa, com o analista aparando o ataque do paciente" (Winnicott, 1971/1982, p. 92). Afirma ainda: "Interpretação verbal nesse ponto não é o aspecto essencial e traz seus próprios perigos. $\mathrm{O}$ aspecto essencial é a sobrevivência do analista e a integridade da técnica psicanalítica” (Winnicott, 1971/1982, p. 92).

Nesse momento da análise, o melhor a fazer é evitar ou adiar a interpretação, permitindo ao paciente a expressão de seus impulsos destrutivos e a consequente transformação do analista em objeto objetivo. Winnicott se lamenta de não ter, por vezes, seguido sua própria recomendação de se abster de interpretar, "esperar até que a fase tenha terminado e então discutir com o paciente o que esteve acontecendo" (Winnicott, 1971/1982, p. 92) - consequentemente, considera ter impedido ou atrasado mudanças "em pacientes numa certa categoria classificatória” (Winnicott, 1971/1982, p. 86).

Uma paciente de pouco mais de vinte anos chega para análise com a queixa de que, desde pequena, sente-se atormentada por certos pensamentos premonitórios, o que a leva a fazer o que chama de "pactos". Assim, por exemplo, pelo fato de ter participado, quando criança, de uma brincadeira em que ela e as amigas faziam perguntas para um espírito (o que ia contra suas crenças religiosas), lhe vem o pensamento de que, como castigo, não conseguirá ter filhos. Além de sentir-se culpada pelo acontecido, imagina que, para conseguir ter filhos, poderá fazer um "pacto" - o qual nunca chega a concretizar -, o que não aplaca, entretanto, sua culpa e angústia pelo fato de ter cogitado fazê-lo.

Inicialmente muito resistente, a paciente vinha de uma experiência anterior de psicoterapia, que havia abandonado por alegar incompetência da terapeuta, a quem costumava se referir com um misto de raiva e desprezo. Procurara novamente tratamento por insistência da mãe e sugestão de um psiquiatra. Em diferentes momentos dessa análise, as sessōes se caracterizavam por fortes reaçóes de raiva e agressividade, acompanhadas, em geral, por demonstraçôes de descrença em relação à capacidade da analista de ajudá-la, de qualquer forma que fosse. Em situaçóes desse tipo, a analista costumava sentir-se impotente, pois nenhuma intervençáo sua parecia surtir efeito. Em outros momentos, especialmente a partir do terceiro ano de análise - quando os pensamentos que haviam constituído sua principal queixa no início da análise passaram a acontecer com uma frequência consideravelmente menor -, a analisanda conseguia fazer uso das interpretaçóes dadas pela analista, associando a partir delas e colocando em movimento o trabalho de análise.

A partir do que estamos propondo aqui, o que nos parece que caracterizou especialmente os dois primeiros anos dessa análise foi uma destrutividade da 
analisanda em relação à analista - relacionada, se acompanharmos Winnicott, a um movimento de "aprender a usar o analista". Nessas sessóes, a analista precisava suportar os impulsos destrutivos da analisanda, não retaliando, para que entáo, em outras sessóes, fosse possível falar sobre essa destrutividade.

Numa sessão durante o segundo ano de análise da paciente, por exemplo, num período em que o que mais parecia incomodá-la era o fato de nunca ter tido um namorado, ela contou que, no intervalo entre aquela e a sessão anterior, havia tido várias crises de choro pelo fato de ter sentido muita raiva. "Raiva da minha mãe, raiva de passar o feriado todo em casa sem ter nada para fazer. Do que adianta ter amigos se ninguém tem interesse em me procurar?". Falou longamente, com raiva, do fato de não ter um namorado. "Acho injusto, por que ninguém se interessa por mim? Tenho raiva de Deus, ele não é bom para mim!". Continuou enumerando seus objetos de ódio: "Tenho raiva da minha mãe, do meu pai, das pessoas que têm namorados, de todo mundo". A paciente também explicitou, e não só atuou, sua raiva da análise: "Fico com raiva de vir aqui, falar, me responsabilizar pelas coisas e não mudar nada. Do que adianta eu perceber aqui que sou responsável por não ter um namorado e isso não contribuir para mudar a situação?". A sessão, caracterizada por muita agressividade verbal e agitação por parte da paciente (que em dois momentos chegou a se levantar e andar pela sala), girou em torno de queixas desse teor. A analista, fora algumas poucas intervençôes, se manteve calada a maior parte do tempo, até porque a paciente parecia estar disposta apenas a rebater qualquer colocação sua.

Em sessóes como essa, em que a paciente apresentava-se extremamente raivosa e agressiva, sem perder nenhuma oportunidade de atacar a analista e o trabalho de análise, a analista sentia que suas colocaçôes não faziam efeito e preferia, muitas vezes, o silêncio. Tal silêncio, nos parece claro agora, estava relacionado a um suportar os impulsos destrutivos da analisanda, o que remete à discussão de Winnicott (1971/1982) a respeito da importância de o analista suportar e sobreviver a esses impulsos, para entáo poder passar a ser usado pelo paciente. Consideramos que esse silêncio, que implicou um não-retaliar por parte da analista, contribuiu para que a analisanda pudesse "destruir" a analista e se preparar para outros momentos da análise - em que lhe foi possível, então, fazer uso da analista e de suas interpretações.

Em vários momentos dessa análise, não interpretar ou simplesmente suportar, sem retaliar, os impulsos destrutivos da analisanda era a forma possível de proceder. O importante não era buscar o sentido da raiva da paciente, mas permanecer com ela em sua agressividade, suportando-a, para depois, em um momento posterior, poder, com a paciente, procurar compreender o que havia se passado. 
Resta ao analista, portanto, em momentos de análises como essa, suportar sem retaliar, não se deixando afetar subjetivamente pela raiva e destrutividade do paciente. Nesse sentido, o analista precisa manter o objeto (paciente e sua raiva) objetivado - assim, ele sobrevive.

\section{Reconhecendo o analista como alteridade}

Para que um objeto seja usado, é necessário que seja lançado fora do domínio subjetivo, permitindo-se uma alteridade. Assim, sugerimos que nas análises que, de acordo com Winnicott, fogem do padrão clássico, o movimento de construir o objeto/analista fora da área de onipotência do analisando implica que este passe a reconhecer o analista como alteridade. Para darmos conta dessa afirmação, algumas palavras sobre a concepção de alteridade que pode ser apreendida da psicanálise winnicottiana são necessárias.

Para Winnicott, no início da vida do sujeito não há diferenciação entre ele e o outro. A alteridade é construída e, portanto, secundária, posterior. Assim, a concepção winnicottiana acerca da alteridade difere substancialmente da de autores como Laplanche (1988) e Jacques André (1996), para quem a alteridade é compreendida como originária.

$\mathrm{Na}$ concepção winnicottiana, a presença materna no momento inicial da vida psíquica do sujeito não é percebida por ele como outro. A mãe que se identifica com as necessidades de seu bebê não se impóe, originariamente, como alteridade, pois, para o bebê, não há, de início, diferenciação entre ele e a mãe. A alteridade do objeto será construída posteriormente, a depender da capacidade do sujeito de colocá-lo fora de sua área de fenômenos subjetivos, permitindo ao objeto uma existência independente das suas identificações projetivas. Um objeto não é, portanto, a priori dotado de alteridade em relação a um sujeito específico, mas sua alteridade poderá vir a ser construída na medida em que puder ser colocado fora da área de controle onipotente do sujeito.

Como a realidade para Winnicott é sempre construída, o sujeito tem papel ativo na criação dos objetos objetivos, que passam a existir fora da área de fenômenos subjetivos. Por outro lado, isso não quer dizer que os objetos existam somente enquanto projeçóes do sujeito. "O bebê cria o objeto, mas o objeto estava lá esperando para ser criado e para se tornar um objeto investido [cathected]" (Winnicott, 1971/1982, p. 89). De forma análoga, pode-se compreender a alteridade como criada ou construída na relação do sujeito com o mundo exterior. 
Nesse processo de construção da alteridade está em jogo o campo dos fenômenos transicionais, situado numa área intermediária de experiência entre o subjetivo e o que é objetivamente percebido. Depois de sair de uma fase em que os objetos são vivenciados exclusivamente como subjetivos, mas antes ainda de poder apreendê-los como objetivos, existindo independentemente de suas identificaçóes projetivas, o sujeito se relaciona com os objetos transicionais. Tal relação, como lembra Ogden (1996, p. 50), "representa a primeira confrontação total do bebê com a alteridade irredutível da realidade do mundo fora dele mesmo". Paradoxalmente, tal confrontação é possível porque o objeto transicional "nunca deixa de ser a criação do bebê, um reflexo dele mesmo no mundo" (Ogden, 1996, p. 50).

$\mathrm{Na}$ constituição da realidade tal qual Winnicott a concebe, os objetos transicionais desempenham papel importante ao introduzirem para o sujeito a alteridade inerente a esses objetos - os quais, ao mesmo tempo, são criados pelo próprio sujeito. Diferentemente da concepção laplancheana segundo a qual a alteridade é tanto originária quanto traumática, é como se a alteridade winicottiana fosse se constituindo aos poucos na vida psíquica do sujeito.

Para as pessoas que chegam à análise com uma dificuldade, conforme a compreensão de Winnicott, na colocação dos objetos fora de sua área subjetiva, a alteridade não é ainda uma questão, uma vez que elas ainda náo construíram os objetos - incluindo o analista - de forma objetiva, independentemente de seu controle onipotente. Afirmar que a análise possibilita ao analisando aprender a "usar o analista", portanto, supóe que, a partir da análise, esse analista poderá passar a existir, para o analisando, fora de sua área de fenômenos subjetivos e como representante de uma alteridade.

Se pudéssemos dividir a análise winnicottiana em duas partes, é como se houvesse uma primeira fase - a fase do cuidado, justamente - cujo objetivo é que o analisando reconheça seu analista como alteridade e possa aprender a usá-lo. $\mathrm{O}$ foco dessa fase é a possibilidade de correção de determinadas falhas ambientais e a posterior construção do analista enquanto objeto objetivo, permitindo o reconhecimento de sua alteridade. A partir daí, o analista poderá ser usado.

$\mathrm{Na}$ fase do cuidado, a regressão, tal qual tematizada por Winnicott, desempenha papel importante. Essa regressão - ao dizer respeito a um retorno a um estado de dependência, característico da relação mãe-bebê, e não a um retorno a antigas zonas erógenas - difere da regressão freudiana. Como sabemos, Freud distingue três tipos de regressão: a tópica, a formal e a temporal. Falar, portanto, em "retorno a antigas zonas erógenas" é fazer referência ao sentido temporal da regressão freudiana, que supóe, conforme Laplanche e Pontalis (1991, p. 440), uma sucessão genética e designa "o retorno do sujeito a etapas ultrapassadas do 
seu desenvolvimento (fases libidinais, relaçóes de objeto, identificações, etc.)" fundamentalmente um retorno a determinadas experiências pulsionais do sujeito.

Embora não negue que a ideia de uma progressão de zonas erógenas faça sentido na compreensão de alguns casos, em outros Winnicott (1967/2000) acha mais útil pensar o desenvolvimento como uma progressão da dependência - inicialmente quase absoluta, do bebê em relação à mãe/meio ambiente - em direção a uma relativa independência. O que está em jogo na regressão à dependência é a adaptação ambiental que ocorreu nessa fase inicial de dependência. Nos casos em que houve um fracasso ambiental no início da vida, a regressão em análise pode ser terapêutica, devendo ser incentivada pelo analista. Isso porque a regressão "traz consigo a oportunidade de corrigir uma adaptação inadequada à necessidade do paciente na sua infância precoce" (Winnicott, 1954/2000, p. 354). Sendo assim, a regressão permite não apenas um retorno a um estado infantil de dependência, mas encerra a possibilidade de que uma situação anterior de adaptação inadequada seja corrigida.

Nos casos em que o paciente não tem ainda a capacidade de usar o analista, a regressão a um estado de dependência pode ser a oportunidade de correção de uma falha ambiental, trazendo, como resultado, a chance de que o analisando reconheça a alteridade do objeto/analista e possa aprender a usá-lo.

Uma falha ambiental poderá impedir ainda o desenvolvimento emocional da criatividade, que, para Winnicott, diz respeito à possibilidade de o indivíduo abordar ou transformar a realidade. A fonte de criatividade está diretamente relacionada à quantidade e à qualidade das provisóes ambientais recebidas pelo sujeito. Se o meio ambiente não foi favorável, deixando de oferecer as condiçóes necessárias, o sujeito não poderá começar a viver criativamente e, consequentemente, não haverá uma área em que possa brincar ou ter experiências culturais.

O que estamos considerando como fase do cuidado da análise relaciona-se, também, à viabilização da atividade criativa daqueles analisandos que, por conta de um ambiente insuficientemente bom, náo conseguem viver de forma criativa. Nesses casos, a regressão em análise poderá contribuir para corrigir falhas ambientais que, como diz Winnicott (1971/1982, p. 68), "sufocaram os processos criativos" do sujeito.

Fornecendo um ambiente suficientemente bom e permitindo a correção de certas falhas ambientais, assim como a expressão da atividade criativa do analisando, a fase do cuidado pode tornar possível ao analisando a constituição do analista enquanto objeto objetivo e o reconhecimento de sua alteridade. A partir daí, o analisando poderá usar o analista e suas interpretaçóes. O caminho estará aberto, então, para outra fase da análise. 


\section{Referências}

André, J. (1996). As origens femininas da sexualidade. Rio de Janeiro: Jorge Zahar.

Figueiredo, L. C. (2009). As diversas faces do cuidar: novos ensaios de psicanálise contemporânea. São Paulo: Escuta.

Laplanche, J. (1988). Novos fundamentos para a psicanálise. Lisboa: Edições 70.

Laplanche, J., \& Pontalis, J.-B. (1991). Vocabulário da psicanálise. São Paulo: Martins Fontes. Ogden, T. (1996). Os sujeitos da psicanálise. São Paulo: Casa do Psicólogo.

Safra, G. (1999). A face estética do self: teoria e clínica. São Paulo: Unimarco.

Souza, O. (2007). Defesa e criatividade em Klein, Lacan e Winnicott. In B. Bezerra Jr., \& F. Ortega (Eds.), Winnicott e seus interlocutores (pp. 315-344). Rio de Janeiro: Relume Dumará.

Winnicott, D. W. (1982). Playing and reality. New York: Tavistock Publications. (Trabalho original publicado em 1971)

Winnicott, D. W. (1990). The aims of psycho-analytical treatment. In D. W. Winnicott (Autor), The maturational processes and the facilitating environment (pp. 166-170). London: Karnac Books. (Trabalho original publicado em 1962)

Winnicott, D. W. (2000). Retraimento e regressão. In D. W. Winnicott (Autor), Da pediatria à psicanálise: obras escolhidas (pp. 347-354). Rio de Janeiro: Imago. (Trabalho original publicado em 1954)

Winnicott, D. W. (2000). The concept of clinical regression compared with that of defence organization. In D. W. Winnicott (Autor), Psycho-analytic explorations (pp. 193-199). Cambridge: Harvard University Press. (Trabalho original publicado em 1967)

Recebido em 18 de novembro de 2013 Aceito para publicação em 30 de junho de 2014

DOI: $10.1590 / 0103-56652015000100012$ 
